Luiz Carlos de Oliveira Cecilio 1,2 Maria de Fátima Brito de Rezende 2 Marta Gama de Magalhães 2 Suely Alves Pinto 2

\section{O pagamento de incentivo financeiro para os funcionários como parte da política de qualificação da assistência de um hospital público, Volta Redonda, Rio de Janeiro, Brasil}

\author{
Financial incentives for employees as part \\ of a policy to upgrade care in a public hospital \\ in Volta Redonda, Rio de Janeiro State, Brazil
}

1 Departamento de Medicina Preventiva e Social, Faculdade de Ciências Médicas, Universidade Estadual de Campinas. C. P. 6111, Campinas, $S P$ 13083-970, Brasil.

cecilioluiz@uol.com.br 2 Hospital São João Batista. Rua Nossa Senhora das Graças 235, Volta Redonda, RJ 27253-610, Brasil. sah@hsjb.org.br

\begin{abstract}
The authors present and analyze six years of regular and steady application of an institutional evaluation policy based on financial incentives in a public hospital in Volta Redonda, Rio de Janeiro State, Brazil, as a part of the hospital's administrative modernization policy. This type of policy is considered implicitly capable of developing a sequence of strategic wagers: (1) release of financial resources for payment of bonuses; (2) creation of an operationally feasible and sensitive evaluation instrument; (3) creation of adequate management mechanisms to improve evaluation policy; (4) employee adherence to the hospital upgrading policy based on the bonus system; and (5) maintenance of the effects of evaluation policy over time. The article discusses the "degree of success" of each of these wagers in an attempt to portray possible gains throughout the process, while also identifying inherent difficulties in such a policy.
\end{abstract}

Key words Institutional Evaluation; Quality Management; Motivation; Quality

Resumo Os autores apresentam e discutem seis anos de aplicação regular e contínua de uma política de avaliação institucional, com uso de incentivo financeiro, em um hospital público, no Município de Volta Redonda, Rio de Janeiro, como parte de seu processo de modernização gerencial. Trabalham com a idéia de que esse tipo de política implica uma cadeia concatenada de apostas: (1) a possibilidade de se viabilizarem recursos financeiros para o pagamento de gratificação; (2) a viabilidade de se construir uma planilha de avaliação sensível e operacionalizável; (3) a capacidade de criação de mecanismos gerenciais competentes para implementar a política de avaliação; (4) a conquista dos trabalhadores, em função da gratificação, para a política de qualificação do hospital e (5) o "não-desvirtuamento" da política de avaliação com o correr do tempo. O artigo faz uma discussão sobre o grau de "sucesso" de cada uma dessas apostas, buscando mostrar alguns ganhos obtidos, mas também apontando as dificuldades inerentes a esse tipo de política.

Palavras-chave Avaliação Institucional; Gestão de Qualidade; Motivação; Qualidade 


\section{Introdução}

O Hospital São João Batista (HSJB) é uma Unidade de Saúde Pública integrada à rede da Secretaria Municipal de Saúde de Volta Redonda, que tem como missão institucional a garantia e viabilização dos preceitos do Sistema Único de Saúde (SUS). Fundado em 1956 como entidade filantrópica Fundação União Hospitalar Gratuita (FUHG), adotou, em 1971, um regime de comodato com a Prefeitura Municipal de Volta Redonda e passou a ser administrado pelo Serviço Autônomo Hospitalar (SAH), uma autarquia pública. O SAH é uma unidade orçamentária autônoma, com direito a uma parte no orçamento municipal e verbas faturadas por intermédio do SUS, sendo seu orçamento estimado, para o ano de 2001, em R\$20.000.000,00. O HSJB caracteriza-se como o hospital de referência da rede básica de saúde de Volta Redonda, atendendo, também, a população dos municípios vizinhos, tendo um perfil assistencial cirúrgico e de grande emergência. Opera 156 leitos distribuídos entre as seguintes unidades assistenciais: Clínica Cirúrgica/Centro Cirúrgico, Clínica Pediátrica e Pronto Socorro (PS) Infantil, PS Adulto, Centro de Tratamento Intensivo (CTI) Adulto, Maternidade, Unidade de Terapia Intensiva (UTI) Neonatal, Clínica Médica e Unidade Intermediária (UI) Adulto. Possui unidades de apoio técnico tais como fisioterapia, diagnose/unidade transfusional e diagnóstico por imagem, além de todos os serviços administrativos e de apoio à assistência (processamento de roupas, serviço de nutrição e dietética, manutenção, recepção, serviços gerais etc.). Faz parte também da sua estrutura assistencial, um ambulatório de especialidades, em sua maioria cirúrgicas. Encontra-se em término de construção a Unidade de Hemodiálise e o Banco de Leite.

Desde 1993, o HSJB vem investindo na construção de um modelo de gestão participativa e descentralizada compromissada com as diretrizes do SUS, em que o ponto de partida e de chegada é o ser humano e sua cidadania. As características do modelo de gestão adotado no HSJB são as seguintes: "desmonte" do organograma verticalizado, com a quebra das linhas de mando hierárquicas, por profissões; ênfase no trabalho das equipes organizadas em unidades de trabalho; profissionalização de gerentes para comando das unidades de trabalho, com a função de "animador da equipe" e articulador dos vários saberes voltados para uma atenção qualificada; gestão colegiada do hospital com participação de todos os gerentes e gestão participativa nas unidades; ênfase no processo de "comunicação lateral” (intergerentes), ênfase na satisfação dos clientes (internos e externos); aposta no potencial humano dos trabalhadores e profissionais de saúde e implantação de indicadores de qualidade (processo de avaliação do desempenho institucional) (Cecilio, 1997).

Apresentamos, neste artigo, a política de avaliação de desempenho adotada pelo hospital desde 1993, bem como apontamos e discutimos alguns pontos positivos e as dificuldades e limitações de tal política. Para caracterizar a política de avaliação, será descrita a estrutura da planilha de avaliação aplicada trimestralmente, com seus indicadores e parâmetros (Tabela 1), a composição da Comissão de Desempenho Institucional (CID) que operacionaliza a avaliação, as fontes de financiamento para a política de avaliação e os valores pagos aos trabalhadores em função do processo de avaliação.

Ao adotarmos uma política de avaliação de desempenho que resulte em pagamento de gratificação financeira para os avaliados, está sendo feita uma cadeia de apostas, isto é, apostamos que se fizermos tal coisa podemos esperar que ocorra o resultado " $\mathrm{x}$ " e que, ocorrendo “x”, podemos esperar "y" e assim por diante. O conceito de aposta usado no mesmo sentido empregado por Carlos Matus (1987) ao trabalhar com a idéia de que, no jogo social, predominam a incerteza e a complexidade, por lidamos sempre com recursos escassos e pelo fato de que todos os outros atores também fazem jogadas, com diferentes intencionalidades, de modo que nossas intervenções são sempre de final aberto, ou seja, são, de fato, apostas. A cadeia de apostas da política de avaliação de desempenho poderia ser apresentada assim: aposta 1: é possível conseguir recursos financeiros expressivos para bancar a política e pagar gratificações que sejam atraentes para os trabalhadores; aposta 2: conseguidos os recursos financeiros, é possível construir, tecnicamente, uma planilha operacionalizável e com sensibilidade suficiente para medir aspectos substantivos da assistência prestada; aposta 3: construída a planilha e viabilizados os recursos financeiros, é possível criar mecanismos gerenciais competentes para operacionalizar adequadamente a planilha, em particular para garantir a geração e sistematização de informação de boa qualidade e o estabelecimento de um bom processo de comunicação com o conjunto dos trabalhadores; aposta 4: uma política de avaliação de desempenho competente que resulta no pagamento de recompensa financeira tem poder suficiente para sensibilizar os trabalhadores e conseguir sua adesão para o pro- 
Planilha de avaliação trimestral de desempenho do Hospital São João Batista, Volta Redonda, Rio de Janeiro, Brasil.

\begin{tabular}{|c|c|c|c|}
\hline Coordenação & Indicador & Parâmetro & Pontuação \\
\hline $\begin{array}{l}\text { Clínica médica, cirúrgica, obstétrica, } \\
\text { PS adulto, CTI neonatal }\end{array}$ & $\begin{array}{l}\text { Número de reuniões } \\
\text { realizadas pela equipe } \\
\text { no trimestre }\end{array}$ & $\begin{array}{l}3 \text { reuniões (multiprofissionais) } \\
\text { no trimestre, sendo uma } \\
\text { por mês }\end{array}$ & $\begin{array}{l}3 \text { reuniões: } 5 \text { pts } \\
2 \text { reuniões: } 2,5 \text { pts } \\
\text { Menos de } 2 \text { reuniões: } 0\end{array}$ \\
\hline $\begin{array}{l}\text { Clínica médica, cirúrgica, obstétrica, } \\
\text { CTI adulto e Ambulatório }\end{array}$ & $\begin{array}{l}\text { Qualidade no preenchimento } \\
\text { dos prontuários }\end{array}$ & $\begin{array}{l}100 \% \text { dos prontuários } \\
\text { preenchidos conforme } \\
\text { protocolo }\end{array}$ & $\begin{array}{l}80 \% \text { a } 100 \%: 5 \text { pts } \\
60 \% \text { a } 70 \%: 2,5 \text { pts } \\
\text { Menos de } 60 \%: 0\end{array}$ \\
\hline CTI adulto & $\begin{array}{l}\text { Taxa de mortalidade/ } \\
\text { índice de Apache }\end{array}$ & Igual ou menor que 1.3 & $\begin{array}{l}\text { Até 1,3: pts } \\
\text { Igual ou maior que 1,3: } 0\end{array}$ \\
\hline Clínica obstétrica & Taxa de cesáreas & $35 \%$ & $\begin{array}{l}\text { Até } 35 \%: 5 \text { pts } \\
36 \% \text { a } 40 \%: 2,5 \text { pts } \\
\text { Maior que } 40 \%: 0\end{array}$ \\
\hline UTI neonatal & Taxa de infecção hospitalar & $35 \%$ & $\begin{array}{l}\text { Até } 35 \%: 5 \text { pts } \\
35 \% \text { a } 40 \%: 2,5 \text { pts } \\
\text { Maior } 40 \%: 0\end{array}$ \\
\hline Clínica Cirúrgica & $\begin{array}{l}\text { Percentual de cirurgias } \\
\text { eletivas suspensas }\end{array}$ & $\begin{array}{l}30 \% \text { com decréscimo de } 5 \% \\
\text { a cada semestre }\end{array}$ & $\begin{array}{l}\text { Até } 30 \%: 5 \text { pts } \\
31 \% \text { a } 35 \%: 2,5 \text { pts } \\
\text { Mias de } 35 \%: 0\end{array}$ \\
\hline Laboratório & $\begin{array}{l}\text { Tempo médio transcorrido } \\
\text { entre solicitação de exame } \\
\text { (hemograma, glicose, EAS) } \\
\text { pela urgência e entrega } \\
\text { do resultado }\end{array}$ & 30 minutos & $\begin{array}{l}\text { Até } 30 \text { minutos: } 5 \text { pts } \\
31 \text { a } 35 \text { minutos: } 2,5 \text { pts } \\
\text { Mais que } 35 \text { minutos: } 0\end{array}$ \\
\hline Imagem & $\begin{array}{l}\text { Percentual de perda de } \\
\text { exames radiológicos por } \\
\text { erro técnico }\end{array}$ & Zero & $\begin{array}{l}0 \text { exames com erro: } 5 \text { pts } \\
1 \% \text { a } 2 \%: 2,5 \text { pts } \\
\text { Mais de } 3 \%: 0\end{array}$ \\
\hline Suprimento & $\begin{array}{l}\text { Percentual de medicamentos } \\
\text { e materiais "sentinelas" que } \\
\text { estouraram estoque mínimo }\end{array}$ & Zero & $\begin{array}{l}0: 5 \text { pts } \\
1 \% \text { a } 5 \%: 2,5 \text { pts } \\
\text { Maior que } 5 \%: 0\end{array}$ \\
\hline Manutenção & $\begin{array}{l}\text { Tempo médio transcorrido } \\
\text { entre solicitação e o conserto } \\
\text { de "marcadores" }\end{array}$ & 12 horas & $\begin{array}{l}\text { Até } 12 \text { horas: } 5 \text { pts } \\
12 \text { a } 24 \text { horas: } 2,5 \text { pts } \\
\text { Mais de } 24 \text { horas: } 0\end{array}$ \\
\hline Recepção & $\begin{array}{l}\text { Percentual de avaliação } \\
\text { positiva pelos usuários }\end{array}$ & $90 \%$ & $\begin{array}{l}90 \% \text { a } 100 \%: 5 \text { pts. } \\
70 \% \text { a } 89 \%: 2,5 \text { pts. } \\
\text { Menos de } 70 \%: 0\end{array}$ \\
\hline Recepção & $\begin{array}{l}\text { Percentual de prontuários } \\
\text { preenchidos devidamente }\end{array}$ & $100 \%$ & $\begin{array}{l}90 \% \text { a } 100 \%: 5 \text { pts } \\
60 \% \text { a } 89 \%: 2,5 \text { pts } \\
\text { Menos de } 60 \%: 0\end{array}$ \\
\hline $\begin{array}{l}\text { Processamento de roupas, nutrição } \\
\text { e dietética e serviços gerais }\end{array}$ & $\begin{array}{l}\text { Percentual de avaliação } \\
\text { positiva dos usuários }\end{array}$ & $90 \%$ & $\begin{array}{l}90 \% \text { a } 100 \%: 5 \text { pts } \\
70 \% \text { a } 79 \%: 2,5 \text { pts } \\
\text { Menos de } 69 \% 0\end{array}$ \\
\hline
\end{tabular}

$\mathrm{CTI}=$ Centro de Terapia Intensiva; PS = Pronto Socorro; UTI = Unidade de Terapia Intensiva; Pts = pontos. 
jeto da direção do hospital, de alguma forma aproximando interesses particulares aos interesses ou objetivos organizacionais que, no caso específico do HSJB, é a proposta de construção de um hospital público, comprometido com a qualidade da assistência e os princípios do SUS; aposta 5: é possível manter, no tempo, o poder de "sedução" e incentivo da planilha, evitando sua burocratização, em particular a incorporação pura e simples da gratificação aos salários dos trabalhadores.

Avaliar o sucesso de uma política da avaliação institucional, parece-nos, teria que passar pela consideração do quanto estas apostas deram "certo", ou melhor, apresentaram os resultados esperados. Nas conclusões do artigo, voltaremos ao tema da cadeia de apostas.

\section{A construção da política de avaliação}

A Planilha de Avaliação de Desempenho adotada pelo HSJB (Tabela 1) é o instrumento para a avaliação e análise dos resultados obtidos pela instituição, aplicada trimestralmente. É constituída por um conjunto de indicadores que pretendem avaliar vários aspectos da vida institucional: a coerência entre as práticas no cotidiano e a missão da instituição, sobretudo o impacto positivo em alguns indicadores que avaliam a qualidade final da assistência prestada; a responsabilidade, interesse e o compromisso do funcionário junto ao público; a satisfação do usuário com o tratamento recebido; o gasto de materiais de forma controlada; o produto do desempenho de algumas categorias profissionais; a participação dos funcionários nas decisões, entre outros. Os indicadores foram pensados como dispositivos para medir a qualidade e fomentar a permanente discussão do tema no cotidiano institucional. É claro que muitos aspectos da vida do hospital ficam fora da planilha, na medida em que ela não tem pretensão de extensividade. O mais importante é que ela estimula que as equipes ponham o tema da qualidade do atendimento como parte de suas preocupações e consigam avaliar aspectos substantivos do seu trabalho. Os indicadores que compõem a planilha avaliam, centralmente, processos e resultados.

A Planilha de Avaliação foi sendo modificada, gradualmente, nos últimos anos, em especial aqueles indicadores que, com o tempo, se revelaram inadequados pelas mais variadas razões: ou não se conseguia informação de boa qualidade para a sua avaliação; ou se atingia, sistematicamente e de forma plena o parâmetro estabelecido, revelando o quanto estava já estabilizado na vida da organização e perdia, assim, sua capacidade de desafiar a equipe; ou se percebia que o indicador não tinha tanta sensibilidade para avaliar determinado aspecto da vida do hospital, devendo por isso ser substituído por outro.

Atualmente, a planilha tem 24 indicadores que medem vários aspectos de praticamente todas as unidades de produção do hospital. Sua última modificação foi feita em 1999, em um momento bem amplo de discussão na instituição, conduzido por duas das autoras deste artigo, como parte de um trabalho de conclusão do Curso de Especialização em Gestão Hospitalar realizado pela Escola Nacional de Saúde Pública, Fundação Oswaldo Cruz, Rio de Janeiro, sob supervisão da Professora Sheyla Lemos.

Para a implantação da Política de Avaliação de Desempenho Institucional, foi criado o Fundo de Desempenho Institucional (FDI). Este fundo é administrado pela CID composta por um representante de cada unidade de produção do hospital e por dois representantes do Colegiado de Gerência (órgão colegiado que congrega todos os gerentes das unidades de produção). A CID tem como atribuições administrar os recursos do Fundo, definir os valores que serão distribuídos a cada avaliação e acompanhar o processo de aplicação da Planilha de Indicadores, analisando os dados de produção e qualidade do serviço prestado por cada unidade do hospital.

O FDI é, portanto, gerenciado diretamente pelos trabalhadores e suas principais fontes são $24 \%$ da receita faturada da própria instituição junto ao SUS, rendimentos de aplicações bancárias e rendimentos de promoções. O pagamento do Incentivo Desempenho acontece trimestralmente e é orientado pelo resultado obtido com a aplicação de uma Planilha de Avaliação de Desempenho que estabelece os indicadores e os parâmetros para a avaliação do hospital como um todo e por unidade de produção.

A cada avaliação trimestral, até 95\% dos recursos acumulados no trimestre são distribuídos entre os funcionários. Se a pontuação da planilha alcançar de $90 \%$ a $100 \%$ do total possível (classificação A), todo o recurso é distribuído. Se a pontuação ficar entre $50 \%$ e $89 \%$ do total possível (classificação B), 70\% dos recursos são utilizados para gratificação e apenas $40 \%$ dos recursos são repassados às equipes, se a pontuação da planilha for inferior a $49 \%$ (classificação C).

No início da experiência, o pagamento do incentivo seguia duas regras principais: era ba- 
seado no desempenho global da instituição, independente do desempenho específico de cada unidade de trabalho (ênfase na cooperação e interdependência das esquipes) e contemplava valores diferenciados para o pessoal de nível universitário, médio e elementar. Atualmente, estas duas regras estão mudadas: são pagos $80 \%$ da gratificação como incentivo baseado no desempenho global da instituição e $20 \%$ da gratificação baseados no desempenho específico das unidades, por meio da análise de um indicador estratégico global avaliado em cada unidade; por outro lado, paga-se o mesmo valor de gratificação para todos os funcionários, não se respeitando mais os três níveis do início da experiência. A taxa de absenteísmo é indicador estratégico que é avaliado em cada unidade. Nesta etapa, a ênfase passa a ser, além da cooperação e interdependência das equipes, na competição produtiva entre elas. A terceira etapa da política, ainda a ser implementada, é o pagamento do incentivo que será pago com base no desempenho global da instituição, no desempenho específico das unidades pela análise do indicador estratégico global em cada unidade e no desempenho específico de cada unidade de trabalho pela análise do seu indicador estratégico específico. Nesse caso, além do estímulo ao resultado coletivo, tenta-se avaliar cada unidade na especificidade de seus processos de trabalho, com indicadores mais "finos" e definidos, de forma dinâmica, no próprio processo de planejamento de cada equipe.

Alguns critérios foram estabelecidos pela Comissão que gerencia o FDI para definir em que casos os trabalhadores não teriam direito a receber o pagamento do incentivo trimestral por seu desempenho individual. Não receberão a gratificação os funcionários que apresentarem uma destas condições: (a) Estejam em gozo de licença para acompanhar cônjuge e/ou outros familiares, justificado e avaliado pela CID, superior a três atestados médicos com o somatório acima de dez dias; (b) Estejam em gozo de licença para tratamento de saúde por prazo superior a dez dias ou com mais de três atestados (mesmo não ultrapassando dez dias); (c) Estejam em gozo de licença para cargo eletivo; (d) Tenham sofrido punição ou advertência por escrito e/ou suspensão; e (e) Tenham faltado ao serviço sem justificativa.

\section{Resultados e discussão}

Voltemos à idéia apresentada na introdução de que uma política de avaliação institucional, com pagamento de gratificação pecuniária, é uma cadeia de apostas.

A aposta 1 (seria possível viabilizar recursos financeiros para a política) mostrou-se viável. O hospital tem conseguido manter, no correr dos últimos sete anos, um fundo com $24 \%$ do seu faturamento provenientes do SUS, o que significou a possibilidade do pagamento de gratificações trimestrais de valor significativo para os trabalhadores. Basta dizer que, em 2000, as gratificações representaram até 7,36 salários a mais ou 20,36 salários / ano para os trabalhadores de nível elementar, 5,66 salários a mais ou 18,6 salários/ano para o pessoal de nível médio e 2,17 salários a mais ou 15,17 salários/ano para o pessoal de nível universitário. Vale destacar que a política de avaliação de desempenho tem sido mantida por uma decisão política da direção do hospital e é, freqüentemente, questionada por outros setores da Prefeitura de Volta Redonda. O hospital vem apresentando, nos anos mais recentes, um crescente déficit no seu custeio, em função do aumento da complexidade dos procedimentos, sem a correspondente contrapartida por parte do SUS. Este fato tem significado a necessidade de uma maior complementação por parte da Prefeitura de Volta Redonda de recursos orçamentários próprios para o custeio do hospital e um certo questionamento da manutenção do pagamento das gratificações nos moldes atuais.

A aposta 2 (que seria possível construir uma planilha operacionalizável e com sensibilidade para medir a qualidade da assistência) tem sido "ganha" com o desenvolvimento da experiência. Uma planilha de avaliação "operacionalizável” implica as seguintes coisas:

- criar indicadores que tenham sensibilidade para captar aspectos importantes da assistência, tanto nos seus processos (formas de organizar a gestão e os processos de trabalho) como nos resultados vividos pelos usuários (dá sensação de segurança e conforto vividos durante a permanência no hospital à resolução do problema vivido pelo usuário) e que sejam vistos como sensíveis e adequados pelos trabalhadores;

- definir parâmetros adequados para avaliar o desempenho dos indicadores. Freqüentemente, não há parâmetros conhecidos de outras experiências para serem tomados como ponto de partida, com raras exceções (Picchai, 2000), até porque os indicadores são, na sua maioria, construídos no hospital. Da mesma forma, como muitas vezes é um indicador novo ("inventado"), nem sempre há uma série histórica da própria instituição para ser tomada como base de construção do parâmetro. Assim, 
a definição dos parâmetros é processual, por aproximações sucessivas, o que leva algum tempo para se chegar ao ponto ideal;

- garantir informação de boa qualidade, confiável, produzida de forma regular, para a construção dos indicadores. O tema da informação na vida do hospital é uma coisa desafiadora. Há uma enorme quantidade de dados produzidos sem nenhuma utilização gerencial, gerando muitos relatórios que não são apropriados internamente, mas sim enviados para alguma instância externa de controle, para "prestação de contas”. Alguns indicadores podem ser monitorados com parte destes dados já existentes (os chamados "dados secundários"), como por exemplo as taxas de mortalidade, de infecção hospitalar ou tempo médio de permanência. Outros, necessitam de "dados primários", a saber, dados que precisam ser coletados especificamente para o indicador, tais como o grau de satisfação do usuário, a qualidade no preenchimento dos prontuários, o tempo transcorrido entre a solicitação de um exame e a entrega do resultado. Aqui, também, ocorre um processo de aproximações sucessivas, de aprendizado e aprimoramento.

A composição da planilha foi mudando com o tempo, de forma que o formato apresentado na Tabela 1 é sua composição atual, sempre em reformulação. Com a consolidação e amadurecimento da política de avaliação, alguns indicadores foram abandonados, novos foram sendo acrescentados, outros modificados e aprimorados. Entre os que foram abandonados, pode-se citar o percentual de faturamento das Autorizações por Internação Hospitalar (AIH) emitidas. Como o hospital alcançava, invariavelmente, $100 \%$ de todas as avaliações, o indicador deixou de ser "desafiador". Entre os modificados, "o tempo transcorrido entre a solicitação de exames de urgência (em geral) e a entrega do resultado" foi focalizado para hemograma, glicose e EAS; a mortalidade no CTI foi substituída pela taxa de mortalidade/índice de Apache; o tempo para atendimento de pedido de manutenção foi focalizado para conserto de torneira e chuveiro e desentupimento de privada na área assistencial. Entre os novos, pode-se citar, como exemplo, a inclusão da avaliação da qualidade de prontuários em novas unidades do hospital, como o CTI adulto, CTI neonatal e PS adulto. Alguns parâmetros foram modificados: a taxa de cesárea passou de $40 \%$ para $30 \%$ em função de parâmetro estabelecido pelo Ministério da Saúde.

Existem protocolos detalhados para orientar o processo de avaliação, tentando conferirlhe o máximo de "objetividade" e isenção. Um bom exemplo disso são os protocolos para avaliação dos prontuários, nos quais se detalha um conjunto de critérios bem rigorosos para que o prontuário seja considerado dentro dos parâmetros desejados.

$O$ grande questionamento que poderia ser feito, nessa aposta, refere-se à capacidade da planilha, com seus pouco mais de 20 indicadores, de sintetizar o desempenho e a qualidade da assistência prestada pelo hospital em todas as suas dimensões. Com certeza que não, mesmo porque seria impossível pensar um instrumento que, sozinho, cumprisse tal propósito. A planilha de avaliação é apenas uma parte do processo mais abrangente de avaliação institucional, que inclui, entre outras coisas, a avaliação sistemática da satisfação dos usuários, os estudos de casos nas enfermarias, o acompanhamento dos custos, e, notadamente, a utilização de um grande número de outros indicadores - que ficam foram da planilha - pelas próprias equipes nos espaços das unidades em que atuam. Em resumo, poderia ser dito que a planilha não consegue, nem tem a pretensão, de avaliar a missão institucional como um todo, significando apenas um esforço de iluminar, de forma bem direcionada e intencional, aspectos que a direção superior e as gerências intermediárias vão definindo como substantivos para a vida da organização em cada momento. Teria a pretensão, sim, de contribuir para a criação de uma cultura institucional de responsabilização e seguimento, de forma regular, por um amplo conjunto de servidores, da qualidade da assistência prestada aos usuários do hospital.

A aposta 3 (seria possível criar mecanismos gerenciais competentes para operacionalizar adequadamente a planilha) tem, também, se cumprido de forma processual, exigindo sempre muita atenção e uma política de capacitação permanente dos quadros do hospital. O sucesso da aposta 3 depende de duas estratégias principais. A primeira delas é a existência de uma comissão interna do hospital, composta por 23 funcionários eleitos pelas várias unidades de produção, a CID, com funções bem definidas de acompanhamento do processo de avaliação. A outra estratégia é o trabalho dos gerentes das unidades, especificamente com a planilha, tanto no sentido de garantir a boa qualidade e regularidade da coleta das informações necessárias para os indicadores, como no de conseguir estabelecer uma boa comunicação com a equipe para discutir os resultados da avaliação. Há dificuldades nestas duas estratégias. Pelo lado da CID, percebe-se uma certa acomodação, um afrouxamento no rigor das 
avaliações e uma comunicação insuficientes com os colegas de unidade. A recente eleição da nova CID, com seus 23 membros e respectivos suplentes, e a realização de um programa de desenvolvimento gerencial para sua melhor capacitação, tem significado uma melhor atuação da comissão que se tem mostrado mais protagonista em relação à política de avaliação institucional. Pelo lado dos gerentes, nota-se um certo descuido na discussão dos resultados da avaliação com as equipes e, mesmo, uma desatenção com a qualidade da coleta dos dados necessários para a fidelidade dos indicadores. Percebe-se uma tendência à acomodação, mas isto será discutido na última aposta. O que vale destacar neste momento é que o modelo de gestão adotado pelo hospital, de recorte horizontal, com coordenação unificada em todas as unidades de trabalho, inclusive as assistenciais, com ênfase na gestão colegiada e participativa em todos os níveis, é facilitador da comunicação e da tomada de decisões necessárias para correção ou melhoria de algum indicador que se mostrar inadequado.

Vale destacar que se tem tido o cuidado -e na nossa avaliação isso não tem ocorrido - para que a CID não funcione como uma estrutura paralela à linha de mando gerencial do hospital, funcionando mais como um espaço de participação e responsabilização de um maior número de funcionários, ao mesmo tempo que fortalece o trabalho gerencial. Não detectamos "disputas” entre a CID e os gerentes, que, ao contrário, têm sido aliados e atores estratégicos para apoiar a implementação de medidas apontadas pela CID como necessárias à melhoria do desempenho da unidade avaliada como um todo.

A aposta 4 (seria possível motivar os trabalhadores com uma política de incentivo baseada na distribuição de recurso financeiros) é bem mais difícil de avaliar que as 3 apostas anteriores. Este tema da conquista da adesão dos trabalhadores para um determinado projeto da direção de qualquer organização, seja ela pública ou privada, é recorrente e central em toda a produção do campo da Teoria das Organização ou da Teoria Geral da Administração. Não há uma "conclusão" única sobre tantas experiências e tantas abordagens desenvolvidas. De Taylor, no início do século XX, com seu "homem econômico", cujo maior interesse seria o dinheiro ou salários melhores, a um autor contemporâneo como Campos (1997), que admite que o dinheiro é criador de subjetividade; dos autores da "escola" das relações humanas que buscavam compreender as necessidades humanas para compreender o comportamento dos homens nas organizações, aos contemporâ- neos autores da Qualidade Total, também procurando compreender (e mobilizar/manipular) as razões mais profundas que movem os homens para frente, desde sempre, quem trabalha com gestão se ocupa, em determinado momento, do tema da conciliação dos desejos e interesses individuais com a macro-racionalidade organizacional, objetiva, "externa" aos homens (Campos, 2000; Cecilio, 2000).

Muitos atores têm se ocupado de estudar, especificamente, a relação entre recebimento de gratificação e a melhoria do desempenho e adesão dos trabalhadores, sem uma conclusão que possa ser considerada "definitiva” (M. L. Cherchiglia, 1995, comunicação pessoal; Kohn, 1995; Numberg, 1997; F. Tobar \& S. Tobar, s.d., comunicação pessoal). Uma política de avaliação de desempenho que usa recursos financeiros como forma de premiação está transitando, digamos assim, por este campo. Com todas as suas perguntas em aberto, seus questionamentos ainda por serem respondidos. No caso do HSJB, o que é possível afirmar é que a gratificação passou a ter importância para os trabalhadores, que eles próprios têm experimentado um protagonismo ativo na condução da política de avaliação e, ainda, que há indicações de que a CDI tem conseguido, em diversas situações, intervir nos processos de trabalho das unidades, procurando aproximá-los dos objetivos mais gerais da organização.

No entanto, seria necessária uma investigação qualitativa mais cuidadosa para avaliar o quanto o pagamento de gratificação, por si só, tem tido poder de conseguir uma maior adesão dos trabalhadores. Achamos mais oportuno julgar que a motivação expressa pelos trabalhadores ao longo da experiência deva ser entendida, em primeiro lugar, como fruto de um determinado contexto organizacional construído/vivenciado no período, contexto no qual o pagamento de incentivos, por mais importante que seja, representa apenas uma parte. Isso não impede que se reconheça, por exemplo, que a definição do absenteísmo como um indicador estratégico resultou numa expressiva queda do mesmo, para algo em torno de $5 \%$ ao mês, considerado excelente se tomados parâmetros existentes na literatura (Picchiai, 2000). Outras melhorias na qualidade da assistência prestada no hospital, que podem ser "creditadas" à política da avaliação e gratificação dos servidores, foram a agilidade na realização dos exames laboratoriais de urgência e uma notável melhoria da qualidade dos prontuários em todas as unidades assistenciais do hospital.

A aposta 5 (seria possível manter, no tempo, o poder de "sedução" da planilha, evitando sua 
burocratização, em particular a incorporação pura e simples da gratificação aos salários dos trabalhadores) para dar certo precisa ser muito trabalhada. Há tendência para uma burocratização do processo avaliatório reconhecida pelos membros da CID, pelos gerentes e pela direção. Há uma percepção de que, com o tempo, os momentos de avaliação se "incorporam à paisagem institucional”, perdem o seu efeito mobilizador. A avaliação do segundo trimestre de 2001, realizada em junho, ao colocar o desempenho do hospital na faixa B e, portanto, significando uma redução do valor da gratificação (seria de $\mathrm{R} \$ 391,00$ se a classificação fosse A, mas acabou sendo de $\mathrm{R} \$ 297,00$, pela classificação B, causou uma comoção entre os trabalhadores. Como os canais de comunicação entre os gerentes e as equipes e mesmo entre os representantes das equipes eleitos para a CDI estavam sendo pouco utilizados, as coisas foram se acomodando. A queda no valor da gratificação foi um dispositivo para mobilizar os trabalhadores do hospital em torno da importância da gratificação, em particular para lembrar o fato de que ela é uma conquista precária, não institucionalizada pela Prefeitura de Volta Redonda, podendo ser abolida a qualquer momento, caso deixe de cumprir sua função principal: contribuir para a qualificação da assistência prestada pelo hospital.

\section{Conclusões}

Olhando, retrospectivamente, a cadeia de apostas implícitas na política de avaliação de desempenho adotada pelo HSJB, vemos que algumas foram bem sucedidas e apresentaram os resultados esperados, enquanto outras nem tanto. A aposta que se concretizou e consolidou, de fato, foi a capacidade de a direção de um hospital público formular e implementar uma inovadora política de avaliação institucional, de forma regular e com significativo reforço nos salários dos seus trabalhadores, no correr dos últimos sete anos. Outra aposta que pode ser considerada como bem sucedida e, portanto, pode contribuir para outras iniciativas semelhantes no setor público, foi a construção, no correr do tempo, de uma planilha com bastante sensibilidade para aspectos substantivos da vida do hospital, com indicadores produzidos de forma regular, valendo-se da informação de boa qualidade e, mais importante, com alto grau de credibilidade junto aos trabalhadores. Por outro lado, é necessário reconhecer que a planilha não consegue, nem era esta a pretensão, avaliar a qualidade da atenção pres- tada em todas as suas dimensões, necessitando ser combinada com outros indicadores incorporados, de forma regular, à gestão do hospital. A política de avaliação de desempenho se consolidou como importante dispositivo de gestão e um importante aliado da direção na condução do hospital em determinada direção. Com certeza, a política de avaliação é um instrumento de controle em rede - descentralizado e com pretensões de legitimidade - mas, certamente, uma potente forma de controle por parte da direção da organização, para além de qualquer consideração sobre os méritos dos “objetivos organizacionais", sejam eles a busca pura e simples de maiores lucros no setor privado ou a construção de um hospital do SUS, comprometido com a defesa da vida. É possível afirmar, também, que o modelo de gestão adotado pelo hospital, em particular seus órgãos colegiados e a concepção de coordenação unificada das áreas assistenciais, foi facilitador da política de avaliação institucional nos moldes em que foi concebida, sobremodo a pretensão de propiciar uma visão mais integrada do hospital, centrada em suas equipes e unidades de produção, mais do que em corporações atuando de modo isolado. A avaliação institucional voltada para processos e resultados que só existem em função de um esforço coletivo, nos distintos espaços de trabalho. Modelo de gestão e política de avaliação se completam e se potencializam mutuamente, um reforçando o outro.

A planilha de avaliação tem funcionado como modeladora de subjetividades no sentido de contribuir para uma maior adesão dos trabalhadores ao projeto da direção de tornar o HSJB um modelo de hospital público? Cremos ser esta a pergunta central e para a qual não é possível, com a metodologia de avaliação da experiência que tem sido usada até agora, obter resposta (s) absolutamente segura (s). Ousamos, apenas, indicar algumas questões que nos têm parecido da maior relevância. Por exemplo, a CID, composta essencialmente por pessoal "da base” (pessoal de nível médio ou elementar) os novos atores incorporados ao processo eleita pelos colegas de trabalho, mediante prática concreta propiciada pelo processo de avaliação de desempenho, tem tomado contato com questões bastante complexas, como os mecanismos institucionais que protegem o segredo e a autonomia do médico. Questão central está no modo de funcionar do hospital cuja análise dos prontuários tem colocado claramente. Avaliar taxas de mortalidade ou de infecção hospitalar, só para dar mais dois exemplos, remetem a um território dado como não 
problemático, que é aquele marcado pelas fortes relações entre saberes e poderes. A aplicação da planilha modela subjetividades, sim. O que é necessário reconhecer; contudo, é que as mudanças não são em linha reta e sempre na direção esperada pela direção, que banca a política de avaliação institucional.

Resta, agora, para encerrar estas reflexões, retomar o tema da permanência, no tempo, do poder de mobilização e incitamento da prática de avaliação institucional. Tivemos oportunidade de vivenciar, ao longo destes sete anos, duas situações ou possibilidades bem diferentes. Uma situação foi a de reconhecer que a planilha estava se burocratizando, "perdendo efeito", "incorporada à paisagem". Os momentos de avaliação trimestral feitos corriqueira e automaticamente, só visíveis ou vividas individualmente, no ato de cada trabalhador receber sua gratificação, um complemento (cada vez mais) necessário dos salários, sempre insuficientes para suprir suas necessidades. Uma forma de repor a perda do poder de compra: interpretação que prevalece entre os trabalha- dores nestes momentos de acomodação. Estamos vivendo, no momento da redação deste artigo, uma outra situação. Hora de reavivar a planilha, retomar seu potencial mobilizador, doador de novos sentidos para a prática das pessoas na vida do hospital. A Comissão de incentivo renovada, problematizando cada indicador, mobilizada. O sentido da gratificação como "complemento do salário" não fica abolida nestes momentos mais mobilizados e problematizadores, mesmo porque a gratificação é uma forma de complementação do salário do trabalhador de saúde. O que se vislumbra nestes ciclos mais mobilizados é que se tem feito, neste anos, o que poderíamos chamar do movimento ascendente de uma espiral: voltamos a passar sobre os mesmos pontos, as mesmas questões, os mesmos velhos problemas; entretanto, podemos enxergá-los de um ponto mais alto, com um pouco mais de clareza e, o que é mais importante, com mais gente compartilhando esta mirada sobre a sempre desafiadora vida do hospital.

\section{Referências}

CAMPOS, G. W. S., 1997. Subjetividade e administração de pessoal: Considerações sobre modos de gerenciar trabalho em equipes de saúde. In: Agir em Saúde, um Desafio para o Público (E. E. Merhy \& R. T. Onocko, org.), pp. 229-266, São Paulo: Editora Hucitec.

CAMPOS, G. W. S., 2000. Um Método para Análise e Co-Gestão de Coletivos. São Paulo: Editora $\mathrm{Hu}-$ citec.

CECILIO, L. C. O., 1997. Inventando a mudança no hospital: O projeto "Em defesa da vida" na Santa Casa do Pará. In: Inventando a Mudança na Saú$d e$ (L. C. O. Cecilio, org.), pp. 187-234, 2a Ed. São Paulo: Editora Hucitec.

CECILIO, L. C. O., 2000. Trabalhando a missão do hospital como facilitador da mudança organizacional: Limites e possibilidades. Cadernos de Saúde Pública, 16:973-983.

KOHN, A., 1995. Por que os planos não funcionam? Revista de Administração de Empresas, 6:13-19.
MATUS, C., 1987. Política, Planificación y Gobierno. Caracas: Fundación Altadir.

NUMBERG, B., 1997. Gerência de Recursos Humanos no Setor Público. Brasília: Escola Nacional de Administração Pública.

PICCHIAI, D., 2000. Dimensionamento Quantitativo de Recursos Humanos em Hospitais Privados e Públicos no Estado de São Paulo. Relatório de Pesquisa 9/2000. São Paulo: Escola de Administração de Empresa, Fundação Getúlio Vargas.

Recebido em 3 de setembro de 2001

Versão final reapresentada em 12 de março de 2002 Aprovado em 10 de maio de 2002 